\title{
High-frequency trading, liquidity withdrawal and the breakdown of conventions in foreign exchange markets
}

\author{
Alexis Stenfors ${ }^{* *}$ and Masayuki Susai ${ }^{*}$
}

\begin{abstract}
Conventions, or "that the existing state of affairs will continue indefinitely, except in so far as we have specific reasons to expect a change" (Keynes, 1936), play a central role in over-the-counter markets. For instance, by allowing expectations about the future to become more harmonised and orderly, they act as stabilisers for the provision of liquidity. Conventions might, of course, change at any time. Nonetheless, by being attached to the daily trading routine and/or integrated within the institutional structure, the confidence in their relevance and validity can be long-lasting. In the foreign exchange market, in particular, where prices are quoted to end-users on demand, market-making banks rely upon a convention to quote each other prices to maintain liquidity. However, the rise of algorithmic and highfrequency trading poses a practical as well as a theoretical challenge to such conventions. By reacting ultra-fast to new information, including to new limit orders submitted by others, markets largely populated with algorithmic traders have become susceptible to a withdrawal of liquidity at an unprecedented speed and scale. Using a high-frequency dataset provided by EBS, this paper investigates the process of liquidity withdrawal from the foreign exchange spot market. By doing so, it considers the crowding out of conventions associated with liquidity provision, traditionally upheld through mutual understanding among financial institutions - in other words, reciprocity and trust among humans.
\end{abstract}

JEL Classification Numbers: B5; D8; F31; G2

Keywords: conventions, liquidity, foreign exchange, limit order book, high-frequency trading, algorithmic trading

\footnotetext{
"Alexis Stenfors (corresponding author), University of Portsmouth, Faculty of Business and Law,
Richmond Building, Portland Street, Portsmouth PO1 3DE, UK. Telephone: +44 (0)23 9284 4183. Email: alexis.stenfors@port.ac.uk

"Masayuki Susai, Nagasaki University, 4-2-1, Katafuchi, Nagasaki, 850-8506 Japan. E-mail: msusai@nagasaki-u.ac.jp
} 


\section{Introduction}

With a daily turnover of around US\$5.1 trillion (BIS 2016), the global foreign exchange market has generally been perceived to be tremendously liquid, even during crises and stress in the financial system. However, the recent rise of algorithmic and high-frequency traders ${ }^{1}$ poses a practical, as well as, theoretical challenge with regards to the traditional way to conceptualise market liquidity. On the one hand, high-frequency traders are often simply portrayed as extremely fast human traders in the mainstream economics and finance literature. Following such a logic, it is easy to see how this technological development could serve to increase market efficiency, the level of competition and the provision of liquidity - and ultimately result in lower transaction costs and an enhanced price discovery process (Bershova and Rakhlin 2013; Broogard et al. 2014; Conrad et al. 2015; Hendershott et al. 2011). On the other hand, critics argue that algorithmic traders, and high-frequency traders in particular, by being able to react and anticipate order flow faster, ultimately crowd out the liquidity traditionally provided by human traders - having unknown consequences from a macro-perspective. For instance, by reacting ultra-fast to new information, including to new orders submitted by humans or other machines, markets increasingly populated with algorithmic traders have become susceptible to a withdrawal of liquidity at an unprecedented speed and scale. As Janet Yellen, Chair of the U.S. Federal Reserve pointed out in August 2017 (Federal Reserve 2017): "Algorithmic traders [...] are a larger presence in various markets than previously, and the willingness of these institutions to support liquidity in stressful conditions is uncertain.” This statement is echoed by the occurrence of several so-called "flash crashes", which have involved violent price moves and sudden liquidity withdrawal in electronic markets. Notably, such events have typically occurred in large and liquid markets traditionally perceived to be exceptionally resilient.

The increase of non-human trading could pose a particular risk for the foreign exchange market, which, in contrast to the stock market, is free from circuit breakers. Large-scale liquidity withdrawal during times of stress could, therefore, act as an "amplifying mechanism" (BIS 2017) and, due to the international nature of the foreign 
exchange market, have a more devastating impact on the global financial system (BIS 2011; Harris 2013). However, with its origins in anonymous and exchange-traded markets, the high-frequency trading debate rarely addresses the unique elements of over-the-counter markets such as foreign exchange, where the provision of liquidity is based upon trust, relationship and ultimately underpinned by conventions.

\section{Foreign exchange market liquidity and conventions}

"Human decisions affecting the future [...] cannot depend on strict mathematical expectations since the basis for making such calculations does not exist,” Keynes (1936, 162-3) wrote. However, because of conventions, or "that the existing state of affairs will continue indefinitely, except in so far as we have specific reasons to expect a change" (Keynes 1926, 152), uncertainty about the future does not necessarily need to result in chaos. By allowing expectations about the future to become more harmonised and orderly, conventions act as important stabilisers for the provision of liquidity.

In contrast to stock markets, the global foreign exchange market is almost exclusively traded over-the-counter and thus dependent on trust and the relationships between the counterparties involved. ${ }^{2}$ Traditionally, the market making function has been undertaken by human traders at banks, who quote prices to customers on demand. However, in order to be able to so, they also have to commit to quoting prices to each other. This convention, to stand ready to supply the market with liquidity, is voluntary and has rested upon a long-standing mutual understanding among banks. Although the convention of liquidity provision in the foreign exchange market is voluntary by nature, it has received a more formalised status by being incorporated in the Model Code. The Model Code, published by the ACI, which, since 1955, has served as the trade organisation for bank, as well as central bank, dealers in the foreign exchange and money markets around the world emphasises the importance of social norms and conventions by stating that "[...] bilateral reciprocal dealing relationships are common [...] and often extend to unwritten understandings between Dealers to quote firm twoway dealing prices" (ACI 2015). Further, the trade organisation sees informal reciprocal 
dealing relationships as "a logical development" and that they "play an important role in providing support and liquidity.”

The term "liquidity" in this sense refers to the concept of market liquidity, which is generally understood to take three dimensions: price (how much it costs to turn around a position over a short period of time), volume (how much can be bought or sold without moving the price) and speed (how long it takes for the price to recover after an "exogenous shock") (Kyle 1985). Price-based liquidity is typically measured as the difference between the bid and offer price at any moment in time (the bid-offer spread). Here, surveys conducted by Cheung and Wong (2000) and Cheung and Chinn (2001) among foreign exchange dealers suggest that the "market convention", rather than indicators directly linked to costs (as suggested by mainstream economic and finance theory), appeared to be the overwhelming driver of the prevailing bid-offer spread in the late 1990s. ${ }^{3}$ Stenfors (2017), using data up to 2016, finds that such conventions may still be dominant in the foreign exchange swap markets. Likewise, volume-based conventions in terms of "standard amounts" in foreign exchange markets have been important in determining how much market liquidity is acceptable to request, or reasonably to provide, at the prevailing bid-offer spread. As Stenfors (2014) argues, market makers may feel a long-term "sense of duty" towards the bank and the institutional setting of the market. In this respect, voluntary liquidity provision could simply be seen as the right thing to do - akin to a "decorum" passed on from previous generations of market makers and therefore a product of past processes (Veblen 1899, 190-1). Speed-based conventions provide guidance as to how long a price for a certain amount of liquidity is deemed to be valid: "[...] a dealer has to assume that a price given to a voice/traditional broker is good only for a short length of time, typically a matter of seconds" (ACI 2009).

Electronic trading does not, per se, pose a threat to such conventions. Humans can, and increasingly do, communicate and interact electronically. High-frequency traders, by contrast, are non-human and anonymous by definition and are thus neither required nor suitable for conventions made by and for humans. 


\section{The illusion of liquidity}

Whereas humans might be able to trade in a matter of seconds, high-frequency traders comfortably deal in milliseconds, microseconds or nanoseconds. This inevitably poses a treat to the social structure of the group hitherto largely composed of human traders at banks, and the "consensus of views held by the body of these individuals as to what is right, good, expedient [...]" (Veblen 1899, 194).

Humans cannot compete with machines in terms of speed. Neither can they form trusting and reciprocal relationships with machines. It is therefore not surprising that high-frequency traders have come to be classified as "dark" and "predatory" (perhaps perversely, given the notorious opaqueness of the foreign exchange market). Moreover, human foreign exchange traders have increasingly complained that "the market disappears as soon as you try to deal," thereby suggesting that conventional market making rules have been challenged, or even broken, through the entry of machines. This is consistent with broader concerns raised that better market liquidity as a result of non-human trading could have a tendency to be accompanied by an "illusion of liquidity" or a "liquidity mirage" (King and Rime 2011; ESRB 2016).

However, investigating the validity of claims of an illusion of liquidity requires a study of events the human trader's eye is unable to see or at least instinctively react to. Rather than a matter of seconds, it would involve the activity that takes place within a shorter time span than it takes for a human to blink (which psychologists approximate to be 0.1-0.4 seconds). To do so, we conduct an empirical investigation using a rare highfrequency dataset from Electronic Broking System (EBS) from 21:00:00 GMT on 8 September 2010 to 20:59:59 GMT on 13 September 2010 (excluding the weekend). EBS the most widely used trading platform among banks and high-frequency traders saw an increase of algorithmic trading from just 2\% in 2004 to around 50\% in 2010 (Moore et al. 2016). We concentrate on the world's most actively traded currency pair, $€ /$ US\$, which, due to the extremely large turnover, has been at the forefront of highfrequency trading in the foreign exchange spot market. ${ }^{4}$ 
On EBS, traders can either submit a market order (demand liquidity) or a limit order (provide liquidity). A trader can also cancel a limit order (withdraw liquidity). ${ }^{5}$

\section{$<$ Table 1 here $>$}

The dataset contains more than 1.4 million $€ /$ US $\$$ limit order submissions during just three 24-hour trading days (see Table 1). This corresponds to an average of 328.6 new orders of at least $€ 1$ million per minute. The widely used proxy for price-based market liquidity (the bid-offer spread) is extremely tight. Furthermore, the market also appears liquid in terms of the standard measure of market depth (how much can be bought and sold at the prevailing best bid-offer spread). Using this volume-based proxy for liquidity, the average market depth of the $€ / U S \$ F X$ spot market for our dataset is $€ 16.2$ million. Thus, at the outset, the market appears very large and liquid - consistent with being the most widely traded currency pair in the world.

However, the size of a financial market can play an important role in creating and sustaining an illusion of liquidity (Stenfors and Lindo, 2016). After a closer empirical investigation of the dataset (see Table 2), a string of observations are notable which, when put together, illustrate that some perceptions can be deceptive.

$<$ Table 2 here $>$

First, despite the tight bid-offer spread, the volume traded at either the bid or offer price, is relatively low. The actual turnover amounts to approximately $€ 12$ billion, which is minuscule when put in relation to the total liquidity provided (over $€ 1.8$ trillion). Likewise, the number of executed trades $(9,151)$ is extremely low in comparison to the number of limit orders submitted $(1,419,630)$.

Second, although the $€ /$ US\$ dataset contains some very large limit orders (the largest is $€ 250$ million), the vast majority (86.5\%) of the limit orders are precisely for $€ 1$ million - which is the minimum allowed size on EBS. Markets populated with high-frequency traders tend to observe a high number of (small) limit orders in relation to market 
orders. The indicators are consistent with a strong presence of such traders, and that the conventional standard amount (historically in the region of 5-10 million) has been eroded, at least in the $€ /$ US\$ foreign exchange spot market.

Third, whereas the total number of limit order submissions, when seen in isolation, portrays a liquid market at all times, the lifetime of the limit orders paints a more nuanced picture. Using the timestamp of the limit order submissions and the corresponding cancellations, we can measure the lifetime of each limit order. The average lifetime of orders is 44.9 seconds. However, the average is boosted by relatively few orders than remain in the limit order book for minutes or even hours. The median lifetime of the limit orders is just 2.5 seconds - more or less in line with the convention of measuring speed-based liquidity in "a matter of seconds".

In order uncover whether a liquidity illusion might be prevalent, we need to study what the human trader's eye is unable to see or at least instinctively react to. Put differently, we want to investigate whether, and how fast, human or non-human traders react to new information entering the EBS universe by withdrawing liquidity. To do so, we begin by using the time-stamp of the 1.4 million limit order submissions as reference points. We then calculate the change in the limit order volume on each side of the order book (buy and sell), following each new order submission - but excluding the limit order submission itself. Given that high-frequency traders have the ability to react faster than humans, we select six different time windows (0.1, 0.2, 0.5, 1, 5 and 10 seconds) to investigate potential differences when allowing for human traders to have time to react - thus providing a deeper insight into the dynamics of the liquidity withdrawal process as a whole. For instance, if the EBS limit order book consists of $€ 15$ million buy orders and $€ 10$ million sell orders immediately prior to a new limit order submission, the limit buy order volume is $€ 15$ million and the limit sell order volume is $€ 10$ million. If, 1 second after a limit order has been submitted, the limit order book contains $€ 12$ million buy orders and $€ 8$ million sell orders, the change in the limit buy order volume is -€3 million and the change in the limit sell order volume is -€2 million. Table 3 shows the results. 
$<$ Table 3 here $>$

As can be seen, a new limit order submission immediately triggers more liquidity provision. However, within 0.2 seconds, the net impact is already negative. The process can be illustrated with an example. Using the hypothetical $€ 15$ million above as a starting point, the limit buy order volume has increased by $€ 0.106$ million to $€ 15.106$ million within 0.1 seconds. Within 0.5 seconds, however, it has decreased by $€ 0.932$ million to $€ 14.068$ million. However, between 1 and 5 seconds, the change in the order book gradually begins to normalise towards zero. The results for the change in the limit sell order book are almost identical.

Thus, a new limit order submission immediately triggers more submissions than cancellations in terms of volume - consistent with the notion that high-frequency traders provide market liquidity. The extra liquidity added up to 0.2 seconds is, however, not accessible to humans. As mentioned previously, it is estimated that it takes 0.1-0.4 seconds for a human to blink. By the time humans, plausibly, have had time to react to the new limit order submission, or when, even, human traders have been able to see the market impact, the submission has caused liquidity withdrawal.

\section{Conclusions}

By being attached to the daily trading routine and/or integrated within the institutional structure, the confidence in the relevance and validity of conventions can be long-lasting (Carvalho 1983-1984; Lawson 1985). Indeed, despite wide-reaching changes in financial markets and the international financial system as a whole, the conventions with regards to liquidity provision in foreign exchange markets have remained remarkably intact for close to half a century. Ultimately, they have been upheld through mutual understanding among financial institutions - in other words, reciprocity and trust among humans. 
Importantly, formal or informal conventions extending to liquidity provision do not extend to machines. As we have shown, high-frequency traders do not simply react faster than humans to new information (such as new orders submitted by others), they do so by withdrawing liquidity before humans instinctively have had the ability to access liquidity. Thus, over time, as slower liquidity providers become relatively less confident in the ability to provide and demand immediate liquidity, the traditional human market making function could be crowded out. This already seems to have taken place among the major currency pairs in the foreign exchange spot market, where electronic platforms such as EBS have become the ultimate liquidity source of choice (Moore et al. 2016) - even during periods of volatility and stress. Whereas this could be seen as a long overdue development in a global financial market dominated by relatively few banks, the gradual breakdown of this institutionalised convention could also pose systemic risks. As we have demonstrated, liquidity might also be withdrawn when it is needed the most. Or more likely: liquidity will be withdrawn when it is needed the most.

\section{Footnotes}

1 Whereas algorithmic trading encompasses a range of mathematical modelling and computer programming in order to enhance the execution process, high-frequency traders use the advantage of speed to trade on new information (faster than humans), to take advantage of price discrepancies (faster than humans) and to provide and withdraw liquidity (faster than humans).

${ }^{2}$ According to the BIS (2016), the exchange-traded foreign exchange market amounts to a daily turnover of US\$0.115 trillion in comparison to the US\$5.067 trillion-a-day OTC foreign exchange market.

${ }^{3}$ The reasons for following such conventions were usually relationship-based or institutional (such as "to maintain an equitable and reciprocal trading relationship”.

${ }^{4}$ The US dollar and the euro are the two largest currencies in the world, and the $€ /$ US $\$$ foreign exchange spot market has an average daily turnover of US\$494 billion (BIS 2013).

${ }^{5}$ In addition to price, volume and buy/sell indicators, we also use the millisecond timestamp provided. A unique trader identification code is attached to each order, allowing us to match order submissions and order cancellations (however, the identities or institutions are not revealed). 


\section{References}

ACI. "The Model Code: The International Code of Conduct and Practice for the Financial Markets.” Paris, France, 2015. Available at http://www.aciforex.co.za/2014/wpcontent/uploads/2015/02/the_model_code_february_2015.pdf. Accessed October 15, 2017.

ACI. "The Model Code: The International Code of Conduct and Practice for the Financial Markets.” Paris, France, 2009. Available at http://www.acipolska.pl/images/pliki/ACI_The_Model_Code.pdf. Accessed October 15, 2017.

Bershova, Nataliya and Dmitry Rakhlin. "High-frequency trading and long-term investors: A view from the buy-side.” Journal of Investment Strategies 2 (2013): 2569.

BIS. "High-frequency trading in the foreign exchange market." Basel, Switzerland: BIS, 2011. Available at http://www.bis.org/publ/mktc05.pdf. Accessed October 15, 2017.

BIS. "Triennial Central Bank Survey - Foreign exchange turnover in April 2013: preliminary global results.” Basel, Switzerland: BIS, 2013. Available at http://www.bis.org/publ/rpfx13fx.pdf. Accessed October 15, 2017.

BIS. “Triennial Central Bank Survey - Foreign exchange turnover in April 2016.” Basel, Switzerland: BIS, 2016. Available at http://www.bis.org/publ/rpfx16fx.pdf. Accessed October 15, 2017.

BIS. “The sterling 'flash event' of 7 October 2016.” Basel, Switzerland: BIS, 2017. Available at http://www.bis.org/publ/mktc09.pdf. Accessed October 15, 2017. 
Brogaard, Jonathan, Terrence Hendershott and Ryan Riordan. "High frequency trading and price discovery." Review of Financial Studies 27 (2014): 2267-2306.

Carvalho, Fernando. J. Cardim. "On the Concept of Time in Shacklean and Sraffian Economics." Journal of Post Keynesian Economics 6, 2 (1983-84): 265-80.

Cheung, Yin-Wong and Menzie Chinn. "Currency traders and exchange rate dynamics: a survey of the US market." Journal of International Money and Finance 20, 4 (2001): 439-71.

Cheung, Yin-Wong and Clement Yuk-Pang Wong. “A survey of market practitioners' views on exchange rate dynamics.” Journal of International Economics 51, 2 (2000): 401-19.

Conrad, Jennifer, Sunil Wahal and Jin Xiang. "High-frequency quoting, trading, and the efficiency of prices." Journal of Financial Economics 116 (2015): 271-291.

ESRB. "Market liquidity and market-making, October 2016." Frankfurt, Germany: ESRB, 2016. Available at https://www.esrb.europa.eu/pub/pdf/reports/20161005_market_liquidity_ma rket_making.en.pdf?797687aead404cddb51d57b0c7dc9604. Accessed 21 July 2017.

Federal Reserve. "Financial Stability a Decade after the Onset of the Crisis." 25 August 2017. Available at https://www.federalreserve.gov/newsevents/speech/yellen20170825a.htm. Accessed October 15, 2017.

Harris, Larry. "What to do about high-frequency trading." Financial Analysts Journal 69, 2 (2013): 6-9.

Hendershott, Terrence, Charles M. Jones and Albert J. Menkveld. "Does Algorithmic 
Trading Improve Liquidity?" The Journal of Finance 66, 1 (2011): 1-33.

Keynes, John Maynard. The General Theory of Interest, Employment and Money. London: Macmillan, 1936.

King, Michael R. and Dagfinn Rime. "The $\$ 4$ trillion question: what explains FX growth since the 2007 survey?” BIS Quarterly Review, December 2010.

Kyle, Albert S. "Continuous Auctions and Insider Trading." Econometrica 53, 6 (1985: $1315-1335$.

Lawson, Tony. "Uncertainty and Economic Analysis." The Economic Journal 95, 380 (1985): 909-27.

Moore, Michael, Schrimpf, Andreas and Vladyslav Sushko (2016) "Downsized FX markets: causes and implications.” BIS Quarterly Review, December 2016.

Stenfors, Alexis. "LIBOR as a Keynesian beauty contest: a process of endogenous deception." Review of Political Economy 26, 3 (2014): 392-407.

Stenfors, Alexis and Duncan Lindo. "The LIBOR Eclipse: political economy of a benchmark.” Research on Money and Finance Discussion Papers, No. 47, SOAS, University of London: 2016.

Stenfors, Alexis. "Bid-Ask Spread Determination in the FX Swap Market: Competition, Collusion or a Convention?" Journal of International Financial Markets, Institutions and Money 2017 (forthcoming).

Veblen, Thorstein. The Theory of the Leisure Class. 1899. Reprint. London: George Allen Urwin, 1957. 
Table 1: Overview of $€ / U S \$$ FX spot limit orders on EBS 8-13 September 2010

Limit order submissions

Total limit order amount

Bid-offer spread

Market depth
$1,419,630$

$€ 1,818,803,000,000$

$0.0083 \%(0.0079 \%)$

$€ 16.167$ million (€13.000 million)

Sources: EBS and authors' calculations.

Table 2: Transactions, market orders, amounts and lifetimes

Transactions (executed amount)

Transactions (number of executed trades)

Limit orders / market orders

Minimum limit order size

Maximum limit order size

Proportion of small limit orders (€1 Mio)

Limit order lifetime Mean (median)

Sources: EBS and authors' calculations.

Table 3: Change in limit order volume
0.1

0.106

0.103
$€ 11,927,000,000$

9,151

$99.43 \%$

$€ 1,000,000$

$€ 250,000,000$

$86.50 \%$

44.9 seconds (2.5 seconds)
Time window (seconds)

Change in limit buy order volume (€mio)

Change in limit sell order volume (€mio)

Sources: EBS and authors' calculations. 